\title{
Genetic and environmental influence on lung function impairment in Swedish twins
}

\author{
Jenny Hallberg ${ }^{1,2,3}$, Anastasia Iliadou ${ }^{4}$, Martin Anderson ${ }^{1,5}$, Maria Gerhardsson de Verdier ${ }^{6}$, Ulf Nihlén ${ }^{6,7}$, \\ Magnus Dahlbäck ${ }^{6}$, Nancy L Pedersen ${ }^{4}$, Tim Higenbottam ${ }^{8,9}$, Magnus Svartengren ${ }^{1 *}$
}

\begin{abstract}
Background: The understanding of the influence of smoking and sex on lung function and symptoms is important for understanding diseases such as COPD. The influence of both genes and environment on lung function, smoking behaviour and the presence of respiratory symptoms has previously been demonstrated for each of these separately. Hence, smoking can influence lung function by co-varying not only as an environmental factor, but also by shared genetic pathways. Therefore, the objective was to evaluate heritability for different aspects of lung function, and to investigate how the estimates are affected by adjustments for smoking and respiratory symptoms.

Methods: The current study is based on a selected sample of adult twins from the Swedish Twin Registry. Pairs were selected based on background data on smoking and respiratory symptoms collected by telephone interview. Lung function was measured as FEV $1, V C$ and DLCo. Pack years were quantified, and quantitative genetic analysis was performed on lung function data adjusting stepwise for sex, pack years and respiratory symptoms.

Results: Fully adjusted heritability for VC was 59\% and did not differ by sex, with smoking and symptoms explaining only a small part of the total variance. Heritabilities for FEV 1 and DLco were sex specific. Fully adjusted estimates were 10 and $15 \%$ in men and $46 \%$ and $39 \%$ in women, respectively. Adjustment for smoking and respiratory symptoms altered the estimates differently in men and women. For FEV ${ }_{1}$ and DLco, the variance explained by smoking and symptoms was larger in men. Further, smoking and symptoms explained genetic variance in women, but was primarily associated with shared environmental effects in men.

Conclusion: Differences between men and women were found in how smoking and symptoms influence the variation in lung function. Pulmonary gas transfer variation related to the menstrual cycle has been shown before, and the findings regarding DLCo in the present study indicates gender specific environmental susceptibility not shown before. As a consequence the results suggest that patients with lung diseases such as COPD could benefit from interventions that are sex specific.
\end{abstract}

\section{Introduction}

The adult individuals' lung function is determined both by the maximal level of lung function growth achieved during childhood and adolescence, and by the rate of decline that follows from the early twenties onwards. Both these are likely to be of importance for later development of respiratory disease, such as COPD. Furthermore, factors as $\mathrm{FEV}_{1}$, and $\mathrm{VC}$ are powerful predictors of mortality $[1,2]$.

\footnotetext{
* Correspondence: magnus.svartengren@ki.se
'Department of Public Health Sciences, Karolinska Institutet, Stockholm,

* Correspondence: magnus.svartengren@ki.se
'Department of Public Health Sciences, Karolinska Institutet, Stockholm, Sweden
}

(c) 2010 Hallberg et al; licensee BioMed Central Ltd. This is an Open Access article distributed under the terms of the Creative Commons Attribution License (http://creativecommons.org/licenses/by/2.0), which permits unrestricted use, distribution, and reproduction in any medium, provided the original work is properly cited. strongly genetically determined both early and later in life, for both men and women [3-6]. Lung function will also be affected by, or co-vary, with other factors, such as smoking and chronic respiratory diseases. However, the relationships between these variables are not always obvious as some smokers never develop symptoms and lung function decline, while some never smokers become ill, etc $[1,2]$. Interestingly, as smoking behaviour in itself is determined both by genes and environment, it can influence lung function by co-varying not only as an environmental factor, but also by shared genetic pathways [3,7]. Further, both respiratory symptoms and 
cigarette smoking have been shown to have a sex related co-variance with pulmonary function measures $[8,9]$. This has brought to attention the possibility that an individual's genes affect his or her sensitivity to factors important for respiratory health [3].

Therefore, the objective of the current cross-sectional study in a Swedish sample of twins was to evaluate heritability for different measures of lung function, and to investigate, by sex, how the estimates are affected by the covariates smoking and respiratory symptoms.

\section{Materials and methods \\ Study population}

The current study (approved by the Ethical Committee at Karolinska Institute, \# 03-461) is based on a selected sample of twins born 1926-1958 from the population based Swedish Twin Registry $[10,11]$ who were contacted using a computer-assisted telephone interview in 1998-2002. The interview included a checklist of common diseases and respiratory symptoms, as well as smoking habits $[10,11]$. Details are shown in the online appendix. From the population of 26,516 twins in pairs where both participated in the telephone interview, 1,030 twins in 515 pairs were selected to participate in more in-depth measures of lung function. The subjects gave written informed consent to participate in the study. To assure that the sample would contain twins with symptoms of respiratory disease (self-reported symptoms of cough, chronic bronchitis, emphysema or asthma) disease concordant and discordant twins were prioritized over symptom free twin pairs. Due to the relatively small number of symptom concordant twins available in the population, pairs were included regardless of smoking habits, while symptom discordant and symptom free pairs were further stratified according to whether none, one, or both of the twins in a pair had a significant smoking history, i.e. had smoked more than 10 pack years (1 pack year is equal to smoking 20 cigarettes per day for 1 year) at the time of inclusion. Table 1 describes the number of twins with the specified combinations of symptoms/smoking habits available from the Swedish Twin Registry. In order to reach the desired number of twin pairs in each category, it was necessary to invite twins from the whole country, as well as twins over a relatively large age span (from 50 yrs with no upper limit), to the study hospital, situated in Stockholm, Sweden. In total, 392 twins (38\%) of 1,030 twins accepted the invitation to participate. Two of the 392 twins participated only by sending in the questionnaire due to poor health. Technically acceptable forced expiratory volume in one second $\left(\mathrm{FEV}_{1}\right)$ and vital capacity (VC) measurements were performed by 378 individuals, resulting in 181 complete pairs. Five individuals had incomplete information on smoking habits,
Table 1 Available, invited and participating twins from the Swedish Twin Registry.

\begin{tabular}{lccccccc}
\hline Group & $\mathbf{1}$ & $\mathbf{2}$ & $\mathbf{3}$ & $\mathbf{4}$ & $\mathbf{5}$ & $\mathbf{6}$ & Total \\
\hline Symptoms: twin1, twin2 & ++ & - & - & - & -+ & -+ & \\
$\begin{array}{l}\text { Smoking > 10 PY: } \\
\text { twin1, twin2 }\end{array}$ & & - & -+ & ++ & - & ++ & \\
\hline No of available & 834 & 12,008 & 7,708 & 4,158 & 1,050 & 758 & 26,516 \\
No of invited & 394 & 128 & 164 & 106 & 86 & 152 & 1,030 \\
No of participating & 130 & 56 & 79 & 43 & 42 & 42 & 392 \\
$\begin{array}{l}\text { Participation in \% of } \\
\text { available }\end{array}$ & 15.6 & 0.5 & 1.0 & 1.0 & 4.0 & 5.5 & 1.5 \\
& & & & & & &
\end{tabular}

Groups: 1) Both have respiratory or minor respiratory symptoms, 2) Both healthy, neither have $>10$ pack years, 3) Both healthy, one twin with $>10$ pack years, 4) Both healthy, both have $>10$ pack years, 5) One twin with respiratory symptoms, one healthy, neither have $>10$ pack years, 6) One twin with respiratory symptoms, one healthy, both have $>10$ pack years,

resulting in 176 complete twin pairs available for covariate analysis. The corresponding figures for acceptable single breath carbon monoxide diffusing capacity (DLco) measurements were 375 individuals in 178 complete twin pairs. After excluding those with missing smoking data, 173 complete pairs remained.

\section{Lung function testing}

All lung function tests were carried out in a single specialized clinic with highly experienced staff. Lung function in terms of $\mathrm{FEV}_{1}, \mathrm{VC}$ and DLco was measured according to American Thoracic Society criteria [12,13], using a Sensormedics 6200 body plethysmograph (SensorMedics; Yorba Linda, CA, USA). Each subject performed several slow and forced vital capacity expirations. $\mathrm{FEV}_{1}$ was compared to the largest obtained $\mathrm{VC}$ and individuals with an obstructive pattern (an $\mathrm{FEV}_{1} / \mathrm{VC}$ ratio 5 units below the predicted value, or $\mathrm{FEV}_{1}$ below $90 \%$ of the predicted value) also performed a new test 15 minutes after bronchodilation with a short-acting beta2-agonist (nebulized Salbutamol). The maximum values for $\mathrm{VC}$ and $\mathrm{FEV}_{1}$ (measured pre- or post bronchodilation) were then used for analysis. Based on lung function, twins could be classified according to GOLD-criteria [14].

Self reported cigarette smoking was assessed at the clinical examination and quantified as pack years.

\section{Determination of twin zygosity}

Zygosity of the sex-liked pairs was determined by the use of a set of DNA markers from blood drawn at the clinical testing. Blood samples were not available for both members in 14 pairs, and zygosity information for these twins was instead obtained at the time of registry compilation on the basis of questions about childhood resemblance. Four separate validation studies using serology and/or genotyping have shown that with these questions $95-98 \%$ of twin pairs are classified correctly [11]. 


\section{Statistical methods}

Respiratory symptoms and pack years were assessed as covariates in the linear multivariate regression models stratified by sex. Analyses were performed with the Stata 9.2 software package (StataCorp LP, College Station, TX, USA)

\section{Quantitative genetic analysis}

Quantitative genetic analysis aims to provide estimates of the importance of genes and environment for the variation of a trait or disease (phenotype). The phenotypic variance is assumed to be due to three latent, or unmeasured, factors: additive genetic factors $\left(\mathrm{a}^{2}\right)$, shared environmental factors $\left(\mathrm{c}^{2}\right)$ or dominant genetic factors $\left(\mathrm{d}^{2}\right)$, and non-shared environmental factors $\left(\mathrm{e}^{2}\right)$, which also include measurement error. Heritability is a term that describes the proportion of total phenotypic variation directly attributable to genetic effects [15]. Twins are ideal for these types of studies as we know how they are genetically related: identical (monozygotic (MZ)) twins share the same genes, whereas fraternal (dizygotic (DZ)) twins share, on average, half of their segregating genes. We also assume that shared environment (for example the presence of a childhood cat, or parental socioeconomic status) contributes to within-pair likeness to the same extent in MZ and DZ twin pairs. By calculating similarity within and between MZ and DZ twin pairs, we can obtain information about the importance of genetic and environmental factors to the variance of the trait in question. One such measure of twin similarity is the intra-class correlation (ICC) [16].

These assumptions can also be illustrated in a path diagram, representing a mathematical model of how genes and environment are expected to contribute to phenotypic variance [11]. Figure 1 illustrates a path diagram for an opposite-sex twin pair. The additive genetic correlation (ra) is set to 1 in MZ twins and 0.5 in likesex DZ twins, based on how genetically related they are, as described above. The shared environment correlation $\left(r_{c}\right)$ is the same for MZ and DZ twins and therefore set to 1 for both groups. By definition there is no correlation for the non-shared environment. The additive genetic, shared, and non-shared environmental variance components are noted as $a_{m}, c_{m}, e_{m}, a_{f}, c_{f}$, and $e_{f}$, for men and women, respectively. The dominant genetic correlation, not included in this figure, is set to 1 in $\mathrm{MZ}$ twins and 0.25 in like-sex DZ twins. The simultaneous estimation of $c^{2}$ and $d^{2}$ is not possible because of statistical issues [17]. However, which factor should be modelled is suggested by the ICC, where $\mathrm{d}^{2}$ is only included in the model if the correlations of $\mathrm{DZ}$ twins are less than half the correlations of MZ twins.

In order to test for sex differences, i.e. whether the same genes and environment contribute to the phenotypic variance in both men and women, different versions of the models can be compared [18]. In the first variance model, we allow the genetic and environmental variance components to be different for men and women, and the genetic correlation $\left(r_{a}\right)$ is free to be estimated for opposite-sexed $\mathrm{DZ}$ twins. For instance, if the genetic correlation is estimated at 0 , it indicates that completely different genes influence the trait in men and women. Variance model 2 tests whether the genetic and environmental variance components are allowed to be different for women and men (e.g. if genetic variance is more important in men than in women), constraining the genetic correlation for members

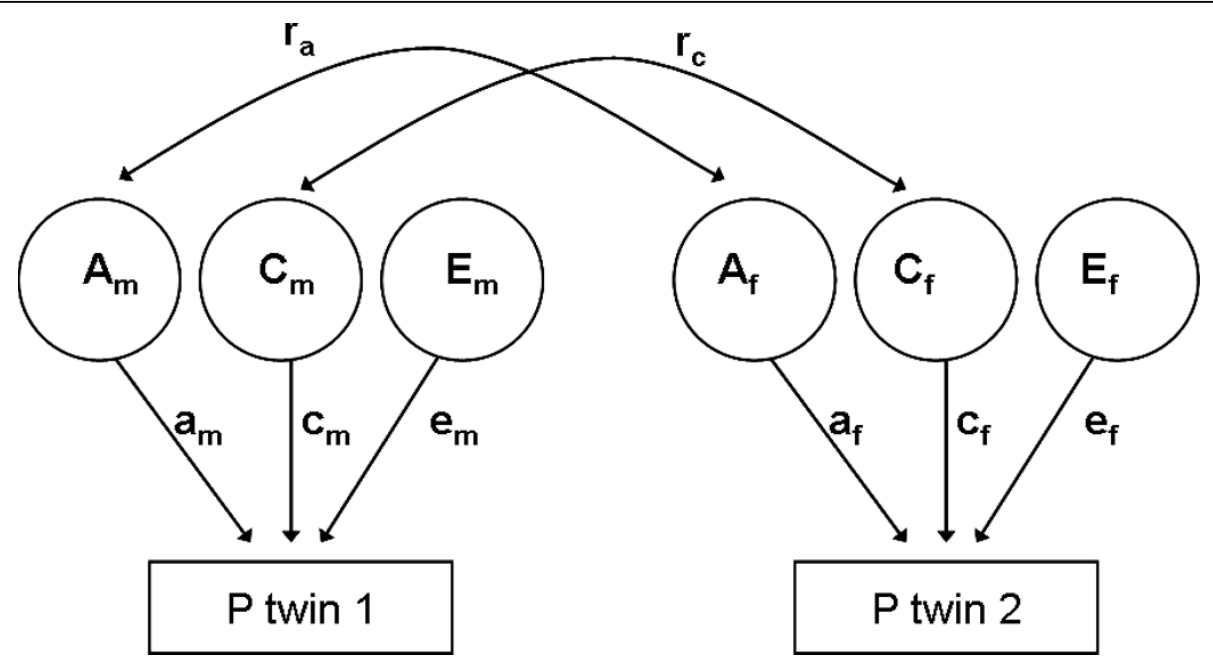

Figure 1 Basic path diagram for an opposite sexed twin pair. $A_{m}, C_{m}, E_{m}, A_{f}, C_{f}$, and $E_{f}$ are the genetic, shared and non-shared environmental variance components for men and women, respectively. The genetic correlation, $r_{a}$, is set free to be estimated in the model, while the shared environmental correlation, $r_{c}$, is set to 1. 
of the opposite-sex twin pairs to 0.5 . Variance model 3 has equal genetic and environmental variance components for men and women. If the fit of this models is not significantly different compared to the previous, we can assume that there are no sex differences in the magnitude of genetic and environmental influences. In summary, the difference in chi-squares between nested models is calculated in order to test which of the models fits better. A significant chi square difference indicates that the model with fewer parameters to be estimated fits the data worse. Model fitting was performed with the Mx program [19].

All models were tested using lung function in percent of predicted value, the same adjusted for pack years, and finally also adjusted for presence of respiratory symptoms.

\section{Results}

\section{Descriptive statistics}

A summary of the available and participating twins is presented in table 1.

Lung function results and covariates (age, height, packyears and symptoms) are presented by zygosity group in table 2 and were found to influence independently and significantly each lung function measure $(\mathrm{p}<0.05)$. GOLD stages for twins with lung function data were: Stage 1 - 53 twins (15\% of the cohort), stage 2 - 42 twins (12\%), stage 3 and above -2 twins (1\%).

\section{Intraclass correlations}

Intraclass correlations (ICC) for unadjusted and adjusted lung function variables are presented in table 3. Comparing ICC for MZ and DZ twins, the presence of additive genetic influences (ICC for MZ twins $>2 \times$ ICC for DZ twins) was indicated for all measures, except for $\mathrm{FEV}_{1}$ in men, where DZ twins showed similar or higher correlation compared to $\mathrm{MZ}$ twins, indicating that additive genetic influences are of less importance. For DLco in women, $\mathrm{MZ}$ correlations were more than twice as high as DZ correlations, showing evidence of genetic dominance. Sex differences were also indicated for $\mathrm{FEV}_{1}$, as unlike sexed DZ twins had lower ICC compared to same-sex DZ.

\section{Sex differences in the genetic influence on measures of} lung function

In order to test for sex differences, structural equation variance models with different assumptions regarding the influence of genetic and environmental effects in men and women were fitted based on the ICC results. The models were then compared to each other to find the most parsimonious one fitting our data. Specific variance model fitting results are available in the online appendix (table 4).

In summary, a model including additive genetic factors (A), shared environmental factors $(C)$ and nonshared environmental factors (E) was used for $\mathrm{VC}$ and $\mathrm{FEV}_{1}$. The comparisons of variance models indicated that the importance of genetic and environmental effects was the same in men and women (figure 2). For $\mathrm{FEV}_{1}$, the same genes are of importance for men and women (comparing model 2 and 1 in table 5), but the influence of genes and environment differs by sex (significantly different fit between model 2 and 3).

For DLco, separate models had to be fitted from the start for men and women. For men, a model containing $\mathrm{A}, \mathrm{C}$ and $\mathrm{E}$ was used (as above), while a model including $\mathrm{A}, \mathrm{E}$ and dominant genetic factors (D) was used for women, since there was evidence for genetic dominance in the latter group (table 6).

\section{Contribution of genes and environment to the total variance}

Figure 3 shows the variance in absolute numbers $(\mathrm{A}+\mathrm{C}+$ $\mathrm{E}=$ absolute total variance), while figure 2 shows the extent to which genetic and environmental factors contributed to the total variance $\left(\% \mathrm{a}^{2}+\% \mathrm{c}^{2}+\% \mathrm{e}^{2}=100 \%\right.$ of total variance).

Unadjusted data show that mainly genetic, but also non-shared environmental influences were of importance for the variance of VC. For FEV 1 and DLco, analyses had to be separated by sex, as indicated above. For both measures, the variance was attributable to both genetic and environmental factors for women, but only to environmental factors in men (figure 2).

Table 2 Mean value ( \pm Standard Deviation) for lung function measures and covariates, by sex and zygosity.

\begin{tabular}{|c|c|c|c|c|c|c|}
\hline & \multicolumn{2}{|c|}{ Men } & \multicolumn{2}{|c|}{ Women } & \multicolumn{2}{|c|}{ Opposite sexed pairs $(n=42)$} \\
\hline & $M Z(n=28)$ & $D Z(n=14)$ & $M Z(n=65)$ & $\mathrm{DZ}(\mathrm{n}=27)$ & Men & Women \\
\hline Age & $60.5 \pm 9.0$ & $59.8 \pm 7.3$ & $59.1 \pm 8.3$ & $60.1 \pm 9.6$ & $58.5 \pm 8.7$ & $58.5 \pm 8.8$ \\
\hline Height & $178.7 \pm 5.7$ & $180.1 \pm 5.3$ & $164.4 \pm 6.2$ & $163.9 \pm 5.5$ & $178.3 \pm 5.5$ & $165.0 \pm 4.8$ \\
\hline Pack yrs ${ }^{1}$ & $11.6 \pm 17.6$ & $22.4 \pm 20.2$ & $9.5 \pm 14.0$ & $13.6 \pm 16.9$ & $15.5 \pm 16.2$ & $11.9 \pm 16.5$ \\
\hline VC in \% pred. & $100.64 \pm 13.00$ & $97.86 \pm 15.83$ & $111.99 \pm 15.42$ & $108.89 \pm 13.94$ & $101.97 \pm 13.04$ & $113.81 \pm 14.90$ \\
\hline $\mathrm{FEV}_{1}$ in $\%$ pred. & $92.97 \pm 14.91$ & $89.70 \pm 18.37$ & $98.96 \pm 16.60$ & $98.21 \pm 15.77$ & $96.27 \pm 15.53$ & $102.68 \pm 14.99$ \\
\hline DLCo ${ }^{2}$ in $\%$ pred. & $95.06 \pm 18.44$ & $92.45 \pm 19.58$ & $87.11 \pm 16.08$ & $79.97 \pm 14.54$ & $91.83 \pm 18.99$ & $89.33 \pm 15.97$ \\
\hline
\end{tabular}

Multiple regression was used in order to test for differences in the mean levels of age, height, packyears and lung function measures (VC, FEV ${ }_{1}$ and DLco) between the zygosity groups. Adjustment for sex was made for height and lung function measures. ${ }^{1}$ Packyears at examination. ${ }^{2} \mathrm{n}$ pairs $\mathrm{MZ}$ male $=28$, DZ male $=15, \mathrm{MZ}$ female $=66, \mathrm{DZ}$ female $=25, \mathrm{OS}=39$. 
Table 3 Intraclass correlations (with $95 \%$ confidence intervals) for unadjusted and adjusted FEV 1 , VC and DLco in a Swedish twin sample by sex and zygosity status.

\begin{tabular}{|c|c|c|c|c|c|}
\hline & \multicolumn{2}{|c|}{ Men } & \multicolumn{2}{|c|}{ Women } & \multirow{2}{*}{$\begin{array}{c}\text { OS } \\
(n=42)\end{array}$} \\
\hline & $M Z(n=28)$ & $D Z(n=14)$ & $M Z(n=65)$ & $D Z(n=27)$ & \\
\hline \multicolumn{6}{|l|}{ vc } \\
\hline Unadjusted & $0.57(0.26 ; 0.78)$ & $0.41(-0.16 ; 0.77)$ & $0.67(0.50 ; 0.78)$ & $0.18(-0.21 ; 0.53)$ & $0.23(-0.08 ; 0.50)$ \\
\hline Adj. PY & $0.49(0.15 ; 0.73)$ & $0.29(-0.29 ; 0.71)$ & $0.67(0.50 ; 0.78)$ & $0.28(-0.12 ; 0.59)$ & $0.25(-0.06 ; 0.52)$ \\
\hline Adj. PY, symptoms & $0.36(-0.01 ; 0.65)$ & $0.18(-0.39 ; 0.65)$ & $0.66(0.50 ; 0.78)$ & $0.26(-0.14 ; 0.58)$ & $0.24(-0.07 ; 0.51)$ \\
\hline \multicolumn{6}{|l|}{$\mathrm{FEV}_{1}$} \\
\hline Unadjusted & $0.28(-0.10 ; 0.59)$ & $0.42(-0.14 ; 0.78)$ & $0.67(0.50 ; 0.78)$ & $0.32(-0.07 ; 0.62)$ & $-0.07(-0.37 ; 0.24)$ \\
\hline Adj. PY & $0.27(-0.12 ; 0.58)$ & $0.25(-0.33 ; 0.69)$ & $0.66(0.50 ; 0.78)$ & $0.39(0.01 ; 0.67)$ & $-0.01(-0.31 ; 0.30)$ \\
\hline Adj. PY, symptoms & $0.18(0.21-0.52)$ & $0.18(-0.39 ; 0.65)$ & $0.65(0.48 ; 0.77)$ & $0.32(-0.06 ; 0.63)$ & $-0.09(-0.38 ; 0.22)$ \\
\hline \multicolumn{6}{|l|}{ DLCO } \\
\hline Unadjusted & $0.58(0.27 ; 0.79)$ & $0.65(0.21 ; 0.87)$ & $0.46(0.24 ; 0.63)$ & $0.06(-0.35 ; 0.44)$ & $0.35(0.04 ; 0.60)$ \\
\hline Adj. PY & $0.37(-0.00 ; 0.65)$ & $0.23(-0.32 ; 0.67)$ & $0.41(0.19 ; 0.60)$ & $0.01(-0.39 ; 0.40)$ & $0.29(-0.03 ; 0.56)$ \\
\hline Adj. PY, symptoms & $0.38(0.00 ; 0.66)$ & $0.29(-0.26 ; 0.70)$ & $0.41(0.17 ; 0.58)$ & $0.02(-0.38 ; 0.41)$ & $0.29(-0.03 ; 0.56)$ \\
\hline
\end{tabular}

${ }^{1} \mathrm{n}$ pairs $\mathrm{MZ}$ male $=28, \mathrm{DZ}$ male $=15, \mathrm{MZ}$ female $=66, \mathrm{DZ}$ female $=25, \mathrm{OS}=39 . \mathrm{PY}=$ pack years

Table 4 Fit statistics from structural equation modelling for VC.

\begin{tabular}{lcccccc}
\hline & -2LL & df & AIC & Diff Chi-2 & Diff df & $\mathbf{p}$ \\
\cline { 2 - 7 } Unadjusted & \multicolumn{7}{c}{} \\
Model 1 & 2827,767 & 343 & 2141,767 & & & \\
Model 2 vs. 1 & 2827,870 & 344 & 2139,870 & 0,103 & 1 & 0,748 \\
Model 3 vs.2 & 2829,011 & 347 & 2135,011 & 1,141 & 3 & 0,767
\end{tabular}

Adj. PY

Model 1

Model 2 vs.1

$\begin{array}{lll}2812,858 & 341 & 2130,858\end{array}$

Model 3 vs.2

$2812,859 \quad 342 \quad 2128,859$

$2815,019 \quad 345 \quad 2125,019$

0,001

2,161

$1 \quad 0,976$

Adj. PY, sympt.

Model $1 \quad 2805,1693392127,169$

Model 2 vs.1 $\quad 2805,215 \quad 340 \quad 2125,215$

$\begin{array}{lllllll}\text { Model } 3 \text { vs. } 2 & 2809,601 & 343 & 2123,601 & 4,386 & 3 & 0,223\end{array}$

Models: 1) rg (genetic correlation) free for DZ opposite-sex twins, ACE different for men and women. 3 ) rg fixed at 0.5 for DZ OS, ACE different for men and women. 4) rg fixed at 0.5 for DZ OS, ACE same for men and women, $\mathrm{df}=$ degrees of freedom, $\mathrm{PY}=$ pack years

Influence of smoking and symptoms on the total variance Adjustment for pack-years and respiratory symptoms resulted in a decrease of the total variance of all lung function measures (VC, $\mathrm{FEV}_{1}$, and DLco) between 7 and $37 \%$.

For VC, the decrease in total variance was due to a small reduction of genetic variance, whilst the nonshared environmental variance was stable after adjustments. For FEV 1 and DLco, the effect of smoking and symptoms was found to be larger in men than in women. The total variance decrease was due to a reduction attributed to genetic variance in women, and shared environmental variance in men.

\section{Discussion}

In the current study all lung function measures (VC, $\mathrm{FEV}_{1}$ and DLco) were shown to be influenced by genetic factors. $F E V_{1}$ and DLco showed sex differences in the relative importance of genes and environment, as well as in how smoking and respiratory symptoms influence the genetic and environmental estimates of the trait. Heritability of $\mathrm{FEV}_{1}$ has been studied before, but for the gas transfer measure DLco, related to clinical findings such as emphysema, the information is new. VC heritability was higher, and without sex differences.

The relationship between smoking and the presence of respiratory symptoms as well as impaired lung function has been long known. More recently, studies of general twin populations have suggested that genetic factors are of importance in individual differences in lung function $[4,6,20]$, and family studies have shown that relatives of subjects with COPD had a higher risk of airflow obstruction than controls [21-23]. In another study of unselected elderly twins in the Swedish twin registry [6], heritability estimates adjusted for smoking were lower for $\mathrm{FEV}_{1}(24-41 \%$ vs. $67 \%)$ but more similar for VC (61\% vs. $48 \%)$ than the current results. In that study no sex differences were found in heritability estimates, but opposite sexed pairs were not included, reducing power to find such differences. Heritability is population specific and will differ between samples that differ in the distribution of environmental risk factors. Even though both populations were of the same nationality and age range, the prevalence of smoking habits and symptoms would have been lower in the unselected second material, which could explain why differences between studies were seen particularly for $\mathrm{FEV}_{1}$, which, as stated above, is known to be susceptible to these factors. 


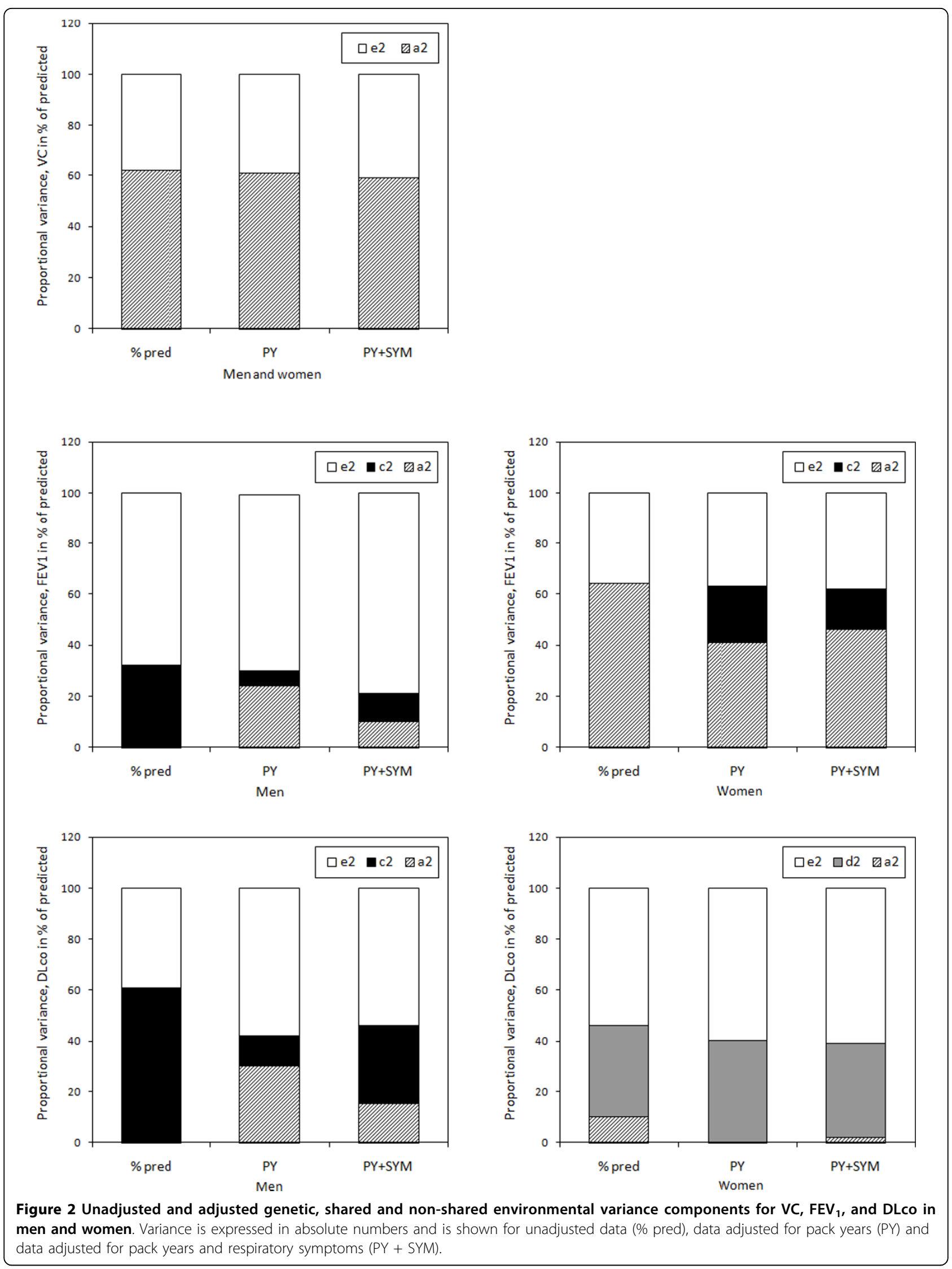


Table 5 Fit statistics from structural equation modelling for FEV . $^{\text {. }}$

\begin{tabular}{lcccccc}
\hline & $\mathbf{- 2 L L}$ & $\mathbf{d f}$ & AIC & Diff Chi-2 & Diff df & $\mathbf{p}$ \\
\cline { 2 - 7 } Unadjusted & \multicolumn{7}{c}{} & & & \\
Model 1 & 2908,199 & 343 & 2222,199 & & & \\
Model 2 vs. 1 & 2908,199 & 344 & 2220,199 & 0,000 & 1 & 0,986 \\
Model 3 vs. 2 & 2916,168 & 347 & 2222,168 & 7,969 & 3 & 0,047
\end{tabular}

Adj. PY

Model $1 \quad 2864,305 \quad 341 \quad 2182,305$

Model 2 vs. $1-2864,305 \quad 342 \quad 2180,305$

$\begin{array}{lllllll}\text { Model } 3 \text { vs. } 2 & 2171,283 & 345 & 2181,283 & 6,978 & 3 & 0,073\end{array}$

Adj. PY, sympt.

\begin{tabular}{lllllll} 
Model 1 & 2845,428 & 339 & 2167,428 & & & \\
Model 2 vs. 1 & 2845,448 & 340 & 2165,448 & 0,021 & 1 & 0,885 \\
Model 3 vs. 2 & 2853,815 & 343 & 2167,815 & 8,367 & 3 & 0,039 \\
\hline
\end{tabular}

Models: 1) rg (genetic correlation) free for DZ opposite-sex twins, ACE different for men and women. 3) $\mathrm{rg}$ fixed at 0.5 for DZ OS, ACE different for men and women. 4) $\mathrm{rg}$ fixed at 0.5 for DZ OS, ACE same for men and women $\mathrm{df}=$ degrees of freedom, $\mathrm{PY}=$ pack years

Table 6 Fit statistics from structural equation modelling for DLCo.

\begin{tabular}{lccc}
\hline Men ACE & $\mathbf{- 2 L L}$ & df & AIC \\
\cline { 2 - 4 } DLco: unadjusted & 727,511 & 82 & 563,511 \\
DLco: adj. PY & 708,851 & 81 & 546,851 \\
DLco: adj. PY, symptoms & 703,134 & 80 & 543,134 \\
\hline Women ADE & $-2 \mathrm{LL}$ & $\mathrm{df}$ & $\mathrm{AIC}$ \\
\cline { 2 - 4 } DLco: unadjusted & 1507,060 & 178 & 1151,060 \\
DLco: adj. PY & 1491,184 & 177 & 1137,184 \\
DLco: adj. PY, symptoms & 1490,454 & 176 & 1138,454 \\
\hline
\end{tabular}

$\mathrm{PY}=$ pack years

Genes and environments contributed differently to the lung function parameters for men and women. Since it is known that genes influence smoking habits, we chose to present results both with and without the adjustment of pack years. Symptoms on the other hand can be a part of COPD. Adjusting for symptoms give estimates of heritability for lung function not associated with symptoms. The differing results for how much these covariates influenced the three measures used in the current study are not unreasonable as the measures represent different aspects of lung function. Smoking induced pathology is likely to be primarily seen in $\mathrm{FEV}_{1}$ and DLco, while VC can remain, at least initially, essentially normal. The approach of adjusting for covariates can however underestimate heritability for the disease itself particularly if they share genetic and environmental effects in common. In women, smoking accounted for some part of the genetic variance, while in men, it accounted for parts of the shared environmental variance. It has been suggested that due to differences in how smoking has been socially accepted in men and women, it is possible that men are more influenced by cultural reasons for smoking than women [24]. Another explanation to the apparent greater proportion in genetic variance in women could be that there is a reduction in absolute range of environmental variance for smoking in women during the mid 1900's, resulting in a proportionate greater observed genetic variance. Thus, genetic variance per se may not have changed, but when seen in relation to environmental variance, it appears to have increased [24].

Hence, smoking and respiratory symptoms could have differential effects on the variance components of men and women. The literature also provides examples of sex-specific effects on different aspect of lung function by genetic determination of physiological and hormonal patterns, such as the connection between aerobic capacity and risk for development of COPD [25], the impact of oestrogen on smoke toxins in the lung [26], and variations in gas transfer over the menstrual cycle [27].

On the phenotypic level, sex differences in the relationship between smoking and lung function impairment have been described in the literature, where women smoke less but have more severe lung function decline and more symptoms $[3,8,9]$. Two recent studies $[28,29]$ have suggested the presence gene-environment interaction, i.e. that the effect of smoking on lung function (here $\mathrm{FEV}_{1}$ ) is dependent on the genotype of the individual. Given our results, we suggest that there are sex differences of importance to the genetic and environmental influence on lung disease. However, the number of twin pairs in the current study was insufficient to evaluate possible interactions. Age is an important covariate in lung disease, but in the current study the number of participants prevented further modelling.

\section{Conclusions}

We have in a sample of twins with and without smoking and respiratory symptoms, shown that not only environment but also genes determine the variability in $\mathrm{VC}$, $\mathrm{FEV}_{1}$ and DLco. Differences between men and women were found in the size of the relative importance of genes, but also in the type of genetic pattern (additive vs. dominant). Adjustments of smoking and respiratory symptoms had also differential effect on men and women for $\mathrm{FEV}_{1}$ and DLco. Further studies on geneenvironment interaction are needed to fully understand the sex differences in respiratory disease. The present study highlights the importance of evaluating genetic and environmental influence on lung function by sex, and suggests that patients with lung diseases such as COPD could benefit from interventions that are sex specific both on the genetic and environmental level. 

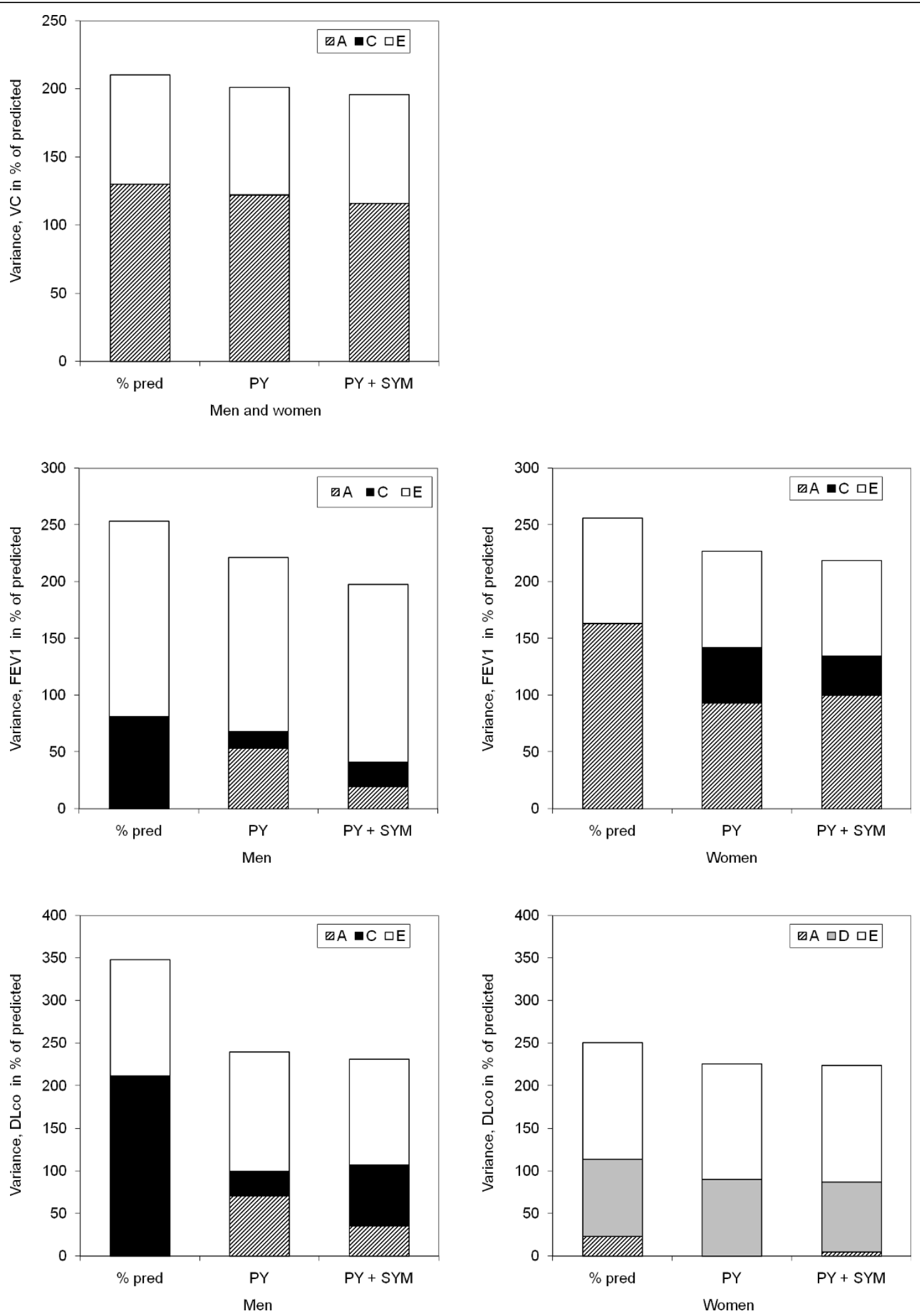

Figure 3 Unadjusted and adjusted genetic, shared and non-shared environmental variance components for VC, FEV 1 , and DLco in men and women. Variance is expressed as percentage of total variance and is shown for unadjusted data (\% pred), data adjusted for pack years (PY) and data adjusted for pack years and respiratory symptoms (PY + SYM). 


\section{Appendix}

\section{Specification of questions from the SALT questionnaire}

1. Do you have recurrent periods of coughing?

If yes:

2. Do you regularly cough up phlegm?

Do you have or have you had:

3. Chronic bronchitis (bronchitis)

4. Emphysema

Chronic bronchitis was defined as:

Recurrent cough with phlegm production, and/or self reported chronic bronchitis and/or self reported emphysema (positive answers to questions $1+2$ or 3 or 4 ).

\section{Acknowledgements}

The authors thank the hospital team Kristina Daniels, Kerstin Magnusson, Isabella Norgren, and Astrid Fernstedt at Södersjukhuset for excellent technical assistance. The study was supported with substantial grants from AstraZeneca, but without any reservations in terms of control of the results. The data collection in SALT was supported by grants from the Swedish Research Council and NIH grant AG 08724. The study was also supported by grants from the Swedish Heart and Lung Foundation.

\section{Author details}

${ }^{1}$ Department of Public Health Sciences, Karolinska Institutet, Stockholm, Sweden. ${ }^{2}$ Centre for Allergy Research, Karolinska Institutet, Stockholm, Sweden. ${ }^{3}$ Department of Pediatrics, Sachs' Children's Hospital, Stockholm, Sweden. ${ }^{4}$ Department of Medical Epidemiology and Biostatistics, Karolinska Institutet, Stockholm, Sweden. ${ }^{5}$ Department of Clinical Physiology, Södersjukhuset, Stockholm, Sweden. ${ }^{6}$ AstraZeneca R\&D, Lund, Sweden. ${ }^{7}$ Department of Respiratory Medicine and Allergology, Lund University, Sweden. ${ }^{8}$ AstraZeneca R\&D, Charnwood, UK. ${ }^{9}$ Current address: Chiesi Farmaceutici S.p.A., Parma, Italy.

\section{Authors' contributions}

$\mathrm{JH}$ planned and conducted the study, as well as drafted the manuscript and did most of the statistical analyses. Al did the calculations on heritability. MA assisted $\mathrm{JH}$ in spirometry issues and supervised the test-leaders. NLP, in charge of the Swedish Twin Registry contributed with valuable knowledge on twin heritability aspects. MS conceived of the study, and participated in its design and coordination. MGdV, UN, MD, TH, MA and MS all participated in the monthly meetings and contributed to the writing of the final paper. All authors read and approved the final manuscript.

\section{Competing interests}

$\mathrm{JH}, \mathrm{Al}, \mathrm{MA}, \mathrm{NLP}$ and MS declare that they have no competing interests. MGdeV, UN and MD are employed at AstraZeneca and own stocks from AstraZeneca. TH was employed at AstraZeneca when the paper was initiated, current affiliation Chiesi Farmaceutici.

\section{Received: 13 February 2010 Accepted: 6 July 2010}

Published: 6 July 2010

\section{References}

1. Beaty $\mathrm{TH}$, Cohen BH, Newill CA, Menkes HA, Diamond EL, Chen CJ: Impaired pulmonary function as a risk factor for mortality. Am J Epidemiol 1982, 116(1):102-13.

2. Peto R, Speizer FE, Cochrane AL, Moore F, Fletcher CM, Tinker CM, Higgins IT, Gray RG, Richards SM, Gilliland J, Norman-Smith B: The relevance in adults of air-flow obstruction, but not of mucus hypersecretion, to mortality from chronic lung disease. Results from 20 years of prospective observation. Am Rev Respir Dis 1983, 128(3):491-500.
3. Hubert HB, Fabsitz RR, Feinleib M, Gwinn C: Genetic and environmental influences on pulmonary function in adult twins. Am Rev Respir Dis 1982, 125(4):409-15.

4. Gibson JB, Martin NG, Oakeshott JG, Rowell DM, Clark P: Lung function in an Australian population: contributions of polygenic factors and the $\mathrm{Pi}$ locus to individual differences in lung function in a sample of twins. Ann Hum Biol 1983, 10(6):547-56.

5. Redline S, Tishler PV, Lewitter Fl, Tager IB, Munoz A, Speizer FE: Assessment of genetic and nongenetic influences on pulmonary function. A twin study. Am Rev Respir Dis 1987, 135(1):217-22.

6. McClearn GE, Svartengren M, Pedersen NL, Heller DA, Plomin R: Genetic and environmental influences on pulmonary function in aging Swedish twins. J Gerontol 1994, 49(6):264-8.

7. Madden PAF, Pedersen NL, Kaprio J, Koskenvuo MJ, Martin NG: The epidemiology and genetics of smoking initiation and persistence: Crosscultural comparisons of twin study results. Twin Research 2004, 7:82-97.

8. Chen Y, Horne SL, Dosman JA: Increased susceptibility to lung dysfunction in female smokers. Am Rev Respir Dis 1991, 143(6):1224-30.

9. Gold DR, Wang X, Wypij D, Speizer FE, Ware JH, Dockery DW: Effects of cigarette smoking on lung function in adolescent boys and girls. $N$ Engl J Med 1996, 335(13):931-7.

10. Lichtenstein P, Sullivan PF, Cnattingius S, Gatz M, Johansson S, Carlstrom E, Bjork C, Svartengren M, Wolk A, Klareskog L, de Faire U, Schalling M, Palmgren J, Pedersen NL: The Swedish Twin Registry in the third millennium: an update. Twin Res Hum Genet 2006, 9(6):875-82.

11. Lichtenstein $P$, De Faire $U$, Floderus $B$, Svartengren $M$, Svedberg $P$, Pedersen NL: The Swedish Twin Registry: a unique resource for clinical, epidemiological and genetic studies. J Intern Med 2002, 252(3):184-205.

12. Miller MR, Hankinson J, Brusasco V, Burgos F, Casaburi R, Coates A, Crapo R, Enright $P$, van der Grinten CP, Gustafsson P, Jensen R, Johnson DC, MacIntyre N, McKay R, Navajas D, Pedersen OF, Pellegrino R, Viegi G, Wanger J: ATS/ERS Task Force. Standardisation of spirometry. Eur Respir J 2005, 26(2):319-38.

13. Macintyre N, Crapo RO, Viegi G, Johnson DC, van der Grinten CP, Brusasco V, Burgos F, Casaburi R, Coates A, Enright P, Gustafsson P, Hankinson J, Jensen R, McKay R, Miller MR, Navajas D, Pedersen OF, Pellegrino R, Wanger J: Standardisation of the single-breath determination of carbon monoxide uptake in the lung. Eur Respir J 2005, 26(4):720-35.

14. Global Strategy for Diagnosis, Management, and Prevention of COPD, Global initiative for chronic obstructive lung disease (GOLD), 2009. [http://www.goldcopd.com].

15. Falconer DS: Introduction to quantitative genetics Harlow, England: Longman 1989.

16. Neale MC, Cardon LR: Methodology for Genetic Studies of Twins and Families Kluwer Academic PublishersDordrecht NL 1992.

17. Evans DM, Gillespie NA, Martin NG: Biometrical genetics. Biol Psychol 2002, 61(1-2):33-51.

18. Neale MC, Martin NG: The effects of age, sex, and genotype on self report drunkenness following a challenge dose of alcohol. Behav Genet 1989, 19:63-78.

19. Neale MC, Boker SM, Xie G, Maes HH: Statistical Modeling Department of Psychiatry, Virginia Institute for Psychiatric and Behavior Genetics, Virginia Commonwealth University, Richmond, VA, 62003.

20. Lundbäck $B$, Lindberg $A$, Lindström $M$, Rönmark $E$, Jonsson $A C$, Jönsson $E$, Larsson LG, Andersson S, Sandström T, Larsson K: Obstructive Lung Disease in Northern Sweden Studies. Not 15 but $50 \%$ of smokers develop COPD?-Report from the Obstructive Lung Disease in Northern Sweden Studies. Respir Med 2003, 97(2):115-22.

21. Silverman EK, Chapman HA, Drazen JM, Weiss ST, Rosner B, Campbell EJ, O'Donnell WJ, Reilly JJ, Ginns L, Mentzer S, Wain J, Speizer FE: Genetic epidemiology of severe, early-onset chronic obstructive pulmonary disease. Risk to relatives for airflow obstruction and chronic bronchitis. Am J Respir Crit Care Med 1998, 157(6 Pt 1):1770-8.

22. McCloskey SC, Patel BD, Hinchliffe SJ, Reid ED, Wareham NJ, Lomas DA: Siblings of patients with severe chronic obstructive pulmonary disease have a significant risk of airflow obstruction. Am J Respir Crit Care Med 2001, 164(8 Pt 1):1419-24. 
23. DeMeo DL, Carey VJ, Chapman HA, Reilly JJ, Ginns LC, Speizer FE, Weiss ST, Silverman EK: Familial aggregation of FEF(25-75) and FEF(25-75)/FVC in families with severe, early onset COPD. Thorax 2004, 59(5):396-400.

24. Kendler KS, Thornton LM, Pedersen NL: Tobacco consumption in Swedish twins reared apart and reared together. Arch Gen Psychiatry 2000, 57(9):886-92.

25. Stevenson CS, Koch LG, Britton SL: Aerobic capacity, oxidant stress, and chronic obstructive pulmonary disease-a new take on an old hypothesis. Pharmacol Ther 2006, 110(1):71-82.

26. Sin DD, Cohen SB, Day A, Coxson H, Paré PD: Understanding the biological differences in susceptibility to chronic obstructive pulmonary disease between men and women. Proc Am Thorac Soc 2007, 4(8):671-4.

27. Farha S, Asosingh K, Laskowski D, Licina L, Sekiguchi H, Losordo DW, Dweik RA, Wiedemann HP, Erzurum SC: Pulmonary gas transfer related to markers of angiogenesis during the menstrual cycle. J Appl Physiol 2007, 103(5):1789-95.

28. Tishler PV, Carey VJ, Reed T, Fabsitz RR: The role of genotype in determining the effects of cigarette smoking on pulmonary function. Genet Epidemiol 2002, 22(3):272-82.

29. Zhai G, Valdes AM, Cherkas L, Clement G, Strachan D, Spector TD: The Interaction of Genes and Smoking on Forced Expiratory Volume: A Classic Twin Study. Chest 2007, 132(6):1772-1777.

doi:10.1186/1465-9921-11-92

Cite this article as: Hallberg et al:: Genetic and environmental influence on lung function impairment in Swedish twins. Respiratory Research 2010 11:92.

\section{Submit your next manuscript to BioMed Central and take full advantage of:}

- Convenient online submission

- Thorough peer review

- No space constraints or color figure charges

- Immediate publication on acceptance

- Inclusion in PubMed, CAS, Scopus and Google Scholar

- Research which is freely available for redistribution

Submit your manuscript at www.biomedcentral.com/submit 